\title{
PHONOCARDIOGRAPHY IN ACUTE RHEUMATIC CARDITIS
}

\author{
BY \\ E. M. M. BESTERMAN
}

From the Special Unit for Juvenile Rheumatism, Canadian Red Cross Memorial Hospital, Taplow, Bucks

Received February 9, 1955

The diagnosis of early rheumatic carditis usually depends upon the detection of murmurs produced by acute valvulitis. It may be difficult to evaluate clinically the significance of certain murmurs occurring in patients with rheumatic fever, though the development of a loud apical pansystolic murmur in a patient already under observation usually presents no diagnostic problem. More frequently a systolic murmur is present when the patient is first seen: then the distinction between systolic murmurs of basal and of mitral origin may be difficult, and in the presence of fever, pain, and resultant tachycardia, it may be impossible to ascertain the significance of the murmur by auscultation alone. The undoubted presence of a mitral diastolic murmur is diagnostic of mitral valvulitis, but the faint short diastolic murmur that first appears is readily confused with a loud third sound or summation gallop, and the clinical distinction between diastolic sounds and murmurs may be uncertain. Similarly it may be difficult to be sure of the presence of the soft aortic diastolic " whiff" of acute aortic valvulitis. It was therefore decided to investigate these murmurs by phonocardiography.

There have been very few reports of the phonocardiographic findings in acute rheumatic carditis. The mitral diastolic murmurs of acute valvulitis have been recorded by Schwarzchild and Feltenstein (1934), Johnston (1935), and McKee (1938). Taquini et al. (1940) investigated the mitral murmurs in a small group of patients with acute carditis: they concluded that the diastolic murmur they had diagnosed clinically in nine cases was due either to summation or near summation of the third and atrial sounds, or else that it was caused by prolongation of the third sound and was not therefore a true murmur. Tachycardia rendered interpretation difficult in some of their cases: although those phonocardiograms recorded at a slower heart rate are of small amplitude, a true diastolic murmur appears to be present in one of these tracings.

\section{Frequencies of MURMURS}

Before starting this work a rough analysis was made of the frequencies of the murmurs of acute rheumatic carditis using an audio-frequency spectrometer. This instrument incorporated 27 band-pass filters set between frequencies of 40 cycles $/ \mathrm{sec}$. and 16 kilocycles $/ \mathrm{sec}$. Each filter was allocated a specified horizontal position for a beam on the screen of a large cathode-ray tube. The beam traced a vertical line at each of the 27 positions, and the height of each vertical deflection indicated the intensity of sound in that particular range. It was not possible to analyse separate phases of the cardiac cycle; therefore the intensity of the sounds and murmurs in one full cycle was determined. The lower graph in Fig. 1 and the cross-hatched area of the upper graph were derived from the findings at the mitral area in eight normal children, and the remainder of the upper graph represents the intensities of sound at each frequency in twelve children with mitral valvulitis. A statistical analysis was made of the differences between the mean values of intensity at each frequency in the normal and abnormal groups. Values for " $t$ " were computed and probability of the differences being due to chance was assessed $(P=<0.01)$. In the case of the mitral murmurs a significant difference was shown between frequencies of 80 and 1600 cycles/sec. Similar results were obtained in the analysis of aortic murmurs. The amplifier used for this investigation had insufficient power to amplify the high frequency murmurs of low intensity, and it was thought that such murmurs might well occupy 
frequencies higher than 1600 cycles/sec. Therefore it was considered desirable to employ a phonocardiograph that would provide adequate records of murmurs composed of frequencies up to $2000 \mathrm{cycles} / \mathrm{sec}$. For this reason a cathode-ray apparatus was designed, the first model of which has already been described (Besterman and Harrison, 1953).

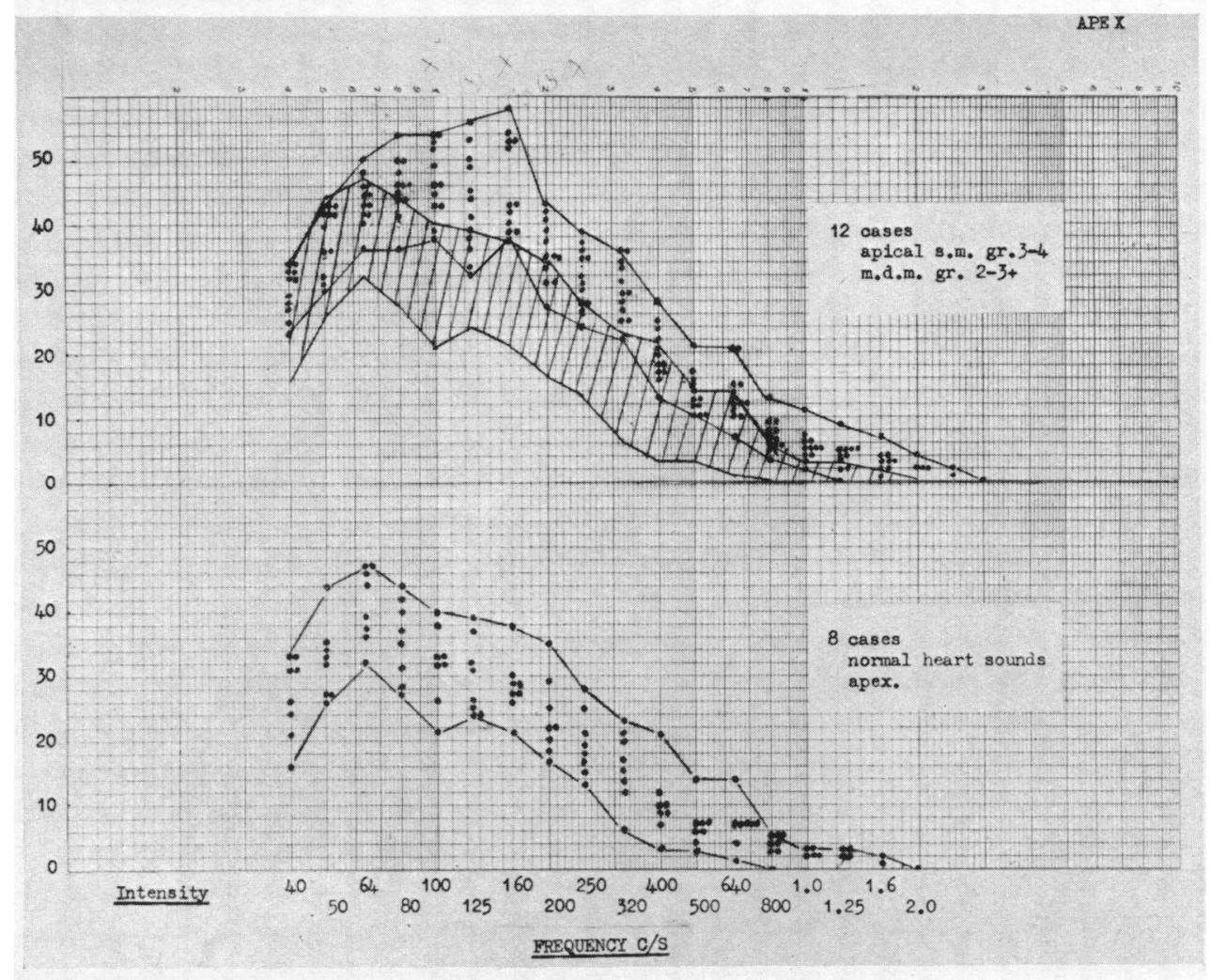

FIG. 1.-Lower graph. Intensity of heart sounds between frequencies of 40 and 2,000 cycles/sec. recorded from the mitral area in eight normal children. Upper graph. Intensity of sounds and murmurs at the mitral area in 12 children with acute mitral valvulitis similarly determined by the audiofrequency spectrometre and superimposed on the normal range (cross hatched area).

Calibration of amplification was provided by the introduction of a 50-cycle signal on to the record of each amplifier. The excursion of this signal was proportional to the amount of gain used in recording on each channel.

The following account concerns the results obtained with this early model in 230 children treated at the Special Unit between 1950 and 1952. Since that time, the original phonocardiograph has been modified and these later recordings form the basis of a more detailed investigation of the murmurs that is being conducted at present.

\section{METHOD}

In the present study murmurs were graded clinically from one to four according to intensity. The phonocardiograms illustrated in this paper were recorded simultaneously with an electrocardiogram, SL. 2. The site of the microphones is represented by the initials MA or LSE, indicating mitral area, and left sternal edge in the third and fourth left interspace. Low, medium, or high pass filters are abbreviated as L.F., M.F., and H.F. respectively. In some phonocardiograms, simultaneous mitral recordings were made using different filters (Fig. 2). Serial records were obtained with the patient lying in the same position, and the microphones placed at identical sites. The degree of amplification was calibrated in some of these phonocardiograms (Fig. 7, 12, and 13). 


\section{HEART SOUNDS}

In patients with early rheumatic carditis no abnormality of the atrial, first, or second heart sounds was detected by phonocardiography. The first heart sound was not accentuated, and no opening snap was ever recorded in these cases.

The third heart sound is detected in normal children more frequently than in adults. In 1951 a preliminary analysis of our phonocardiograms showed accentuation of the third sound in many children with mitral incompetence (Fig. 2). Although we were not then aware that this accentuation

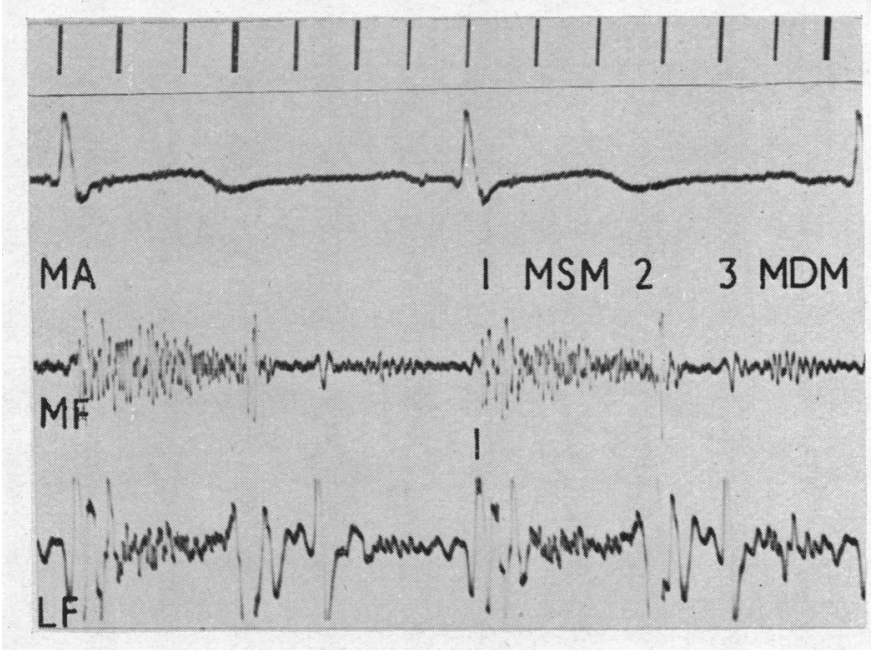

FIG. 2.-Acute rheumatic mitral incompetence with a pansystolic murmur and an accentuated third heart sound initiating a short mitral diastolic murmur.

had been previously described, we have since found that Bouillaud (1835) noted an extra sound in a patient with acute carditis and an apical systolic murmur; and that Coombs (1924) and Sprague and White (1926) had noted a loud third sound in children with mitral incompetence.

This sign had probably been overlooked by us previously as the third heart sound commonly initiated a mitral diastolic murmur of similar frequency with which the sound could have been easily confused on auscultation. Once attention had been drawn to accentuation of the third sound on the phonocardiogram, the louder sound was detected clinically in many patients with mitral incompetence, and proved to be a helpful sign in the diagnosis of this valve lesion.

Subsequently Brigden and Leatham (1953) have described an audible third sound in 50 per cent of 30 adults suffering from pure mitral incompetence; and further confirmation has been provided by Wood (1954) who noted this sound in 85 per cent of patients with well developed incompetence.

It is presumed that the accentuation of the third heart sound in mitral incompetence is due to the increased rate of early ventricular diastolic filling.

\section{Systolic Murmurs}

In 1830 Elliotson described a bellows murmur associated with acute endocarditis: at necropsy he noted deformities of the mitral valve which he considered sufficient to have caused mitral regurgitation. Hope (1839) stated that in 1831 he had been the first to appreciate the diagnostic significance of murmurs in rheumatic heart disease. He believed that mitral regurgitation was the most important lesion of early rheumatic carditis and described the characteristic features of the systolic 
murmur; these included maximum intensity at the apex, loudness, and early onset often concealing the first heart sound. Disagreement still exists concerning the mechanism by which the valve becomes incompetent. Dilatation of the ventricle and valve ring has been invoked to explain this lesion by Owen (1886), Sturges (1894), and Thayer (1925). The other view that inflammation and swelling of the cusps prevent proper closure of the valve, thus allowing regurgitation of blood during systole, was advanced by Todd (1849), and Cheadle (1889); and both Coombs (1924) and Levine (1945) have agreed that this may be the mechanism by which incompetence is produced in early carditis. Besterman and Thomas (1953) have shown that cardiac enlargement does not occur in early acute rheumatic heart disease, and we believe that acute valvulitis alone causes mitral incompetence in these cases. However, cardiac enlargement and dilatation of the mitral ring are usually found in cases of established mitral incompetence.

A basal systolic murmur is commonly present in normal children, usually of maximum intensity in the pulmonary area, and frequently conducted to the apex. An innocent murmur was detected in the mitral area in 90 per cent of normal children by McKee (1938); and if tachycardia is present it may be difficult to distinguish from an organic mitral murmur. In 1846 Barlow observed the fundamental distinction between systolic murmurs of basal and mitral origin according to their duration in systole. Using the phonocardiograph, Lian and Racine in 1933 described the pansystolic duration of the mitral murmur (Fig. 2) and this characteristic has subsequently been confirmed by Cossio (1937) and Leatham (1951). By contrast, organic basal systolic murmurs, whether of pulmonary or aortic origin, reach maximum intensity in mid-systole and end before the second sound (Lewis, 1915; Castro et al., 1947; and Leatham, 1951 and 1952). "Innocent " or " benign" basal systolic murmurs are of similar character, but usually softer, of grade one or two intensity, and may be early or delayed in onset (Fig. 3).

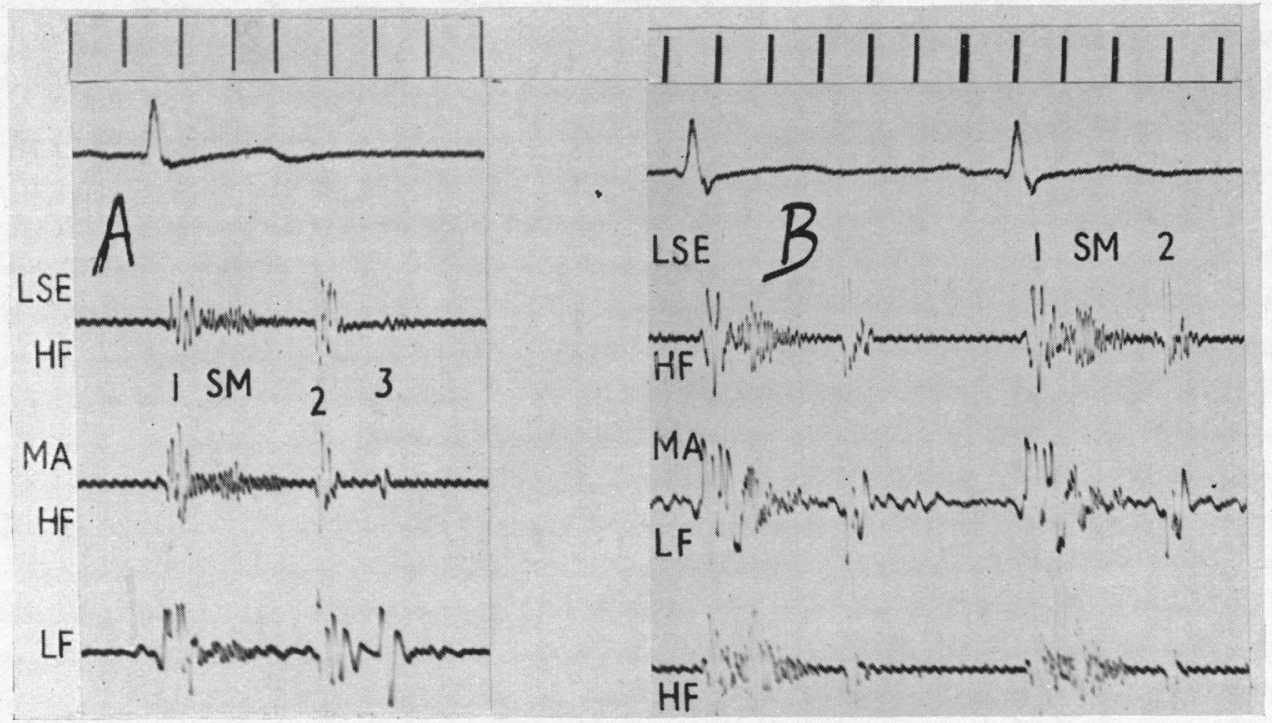

FIG. 3.-Recordings of benign basal systolic murmurs conducted to the mitral area; (A) early onset, (B) delayed onset.

In acute rheumatic carditis phonocardiography is of particular value in assessing the duration, and therefore the significance, of systolic murmurs in the mitral area. This application of the phonocardiogram is illustrated by Fig. 4A. The patient had signs of established aortic valve disease, without cardiac enlargement, together with an apical systolic murmur of uncertain origin: a pre- 
systolic murmur was also present, possibly due either to an Austin Flint effect, or else to mitral valvulitis. The phonocardiogram demonstrated a distinct pansystolic mitral murmur. Recovery ensued, and the signs of mitral valvulitis disappeared, leaving only the murmurs of established aortic valve disease (Fig. 4B). In this patient a second attack of rheumatic fever had been accompanied by transient mitral valvulitis as evidence of further carditis: this knowledge was only conclusively provided by the phonocardiogram.

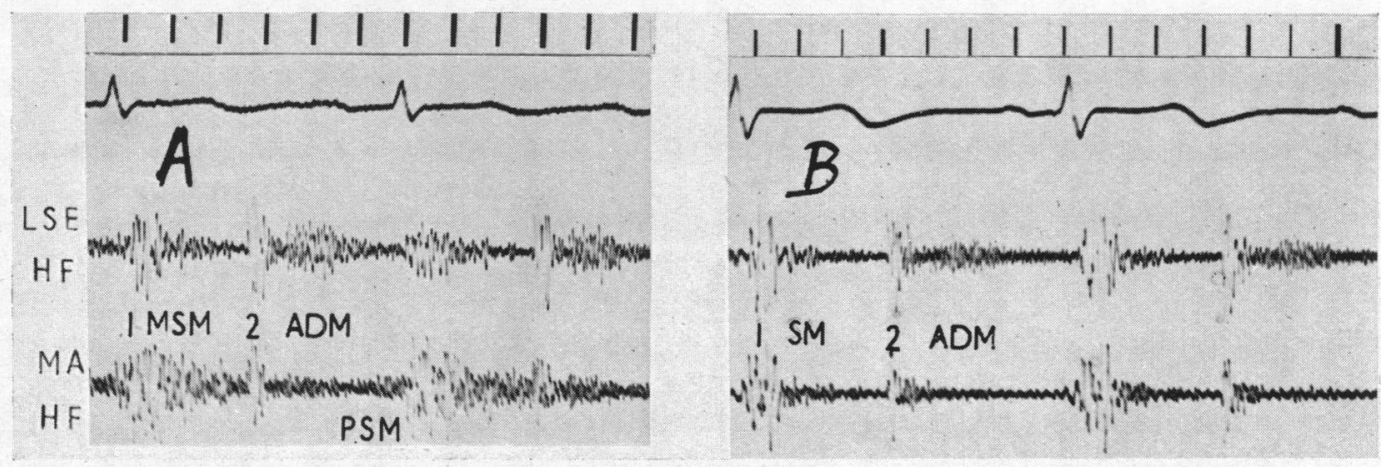

FIG. 4.-(A) Second attack of rheumatic carditis: phonocardiogram showing murmurs of aortic incompetence and acute mitral valvulitis. (B) Disappearance of mitral and persistence of aortic murmurs.

The development of a mitral systolic murmur usually occurs early in the course of acute carditis, often preceding admission to hospital, and is observed only infrequently. Fig. 5A was recorded from a patient with acute rheumatic pericarditis without evidence of valvulitis. A recurrence of rheumatic activity occurred during convalescence and mitral incompetence developed under observation (Fig. 5B).

In some patients with mitral pansystolic murmurs the murmur was most intense in late systole. Fig. 6 demonstrates the usual mitral systolic murmur which was of grade 3 intensity, and the subsequent change when it showed late systolic accentuation, and its eventual disappearance, leaving

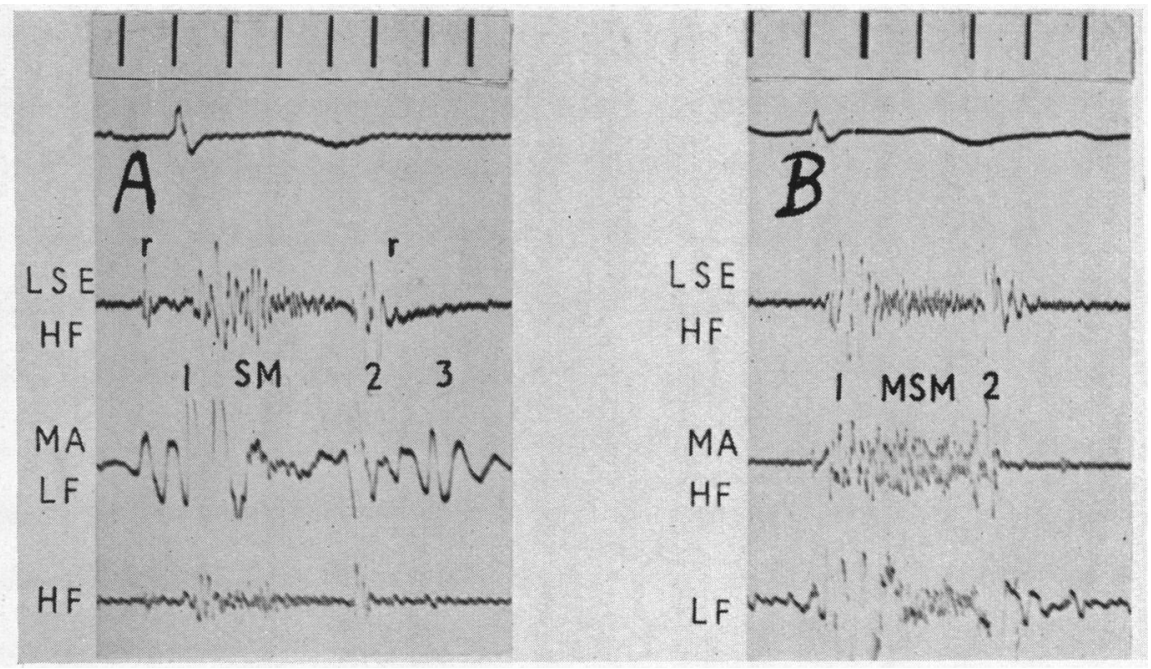

FIG. 5.-(A) Acute rhuematic pericarditis with a basal systolic murmur; (B) Subsequent recurrence of rheumatic carditis with development of a pansystolic mitral murmur. 


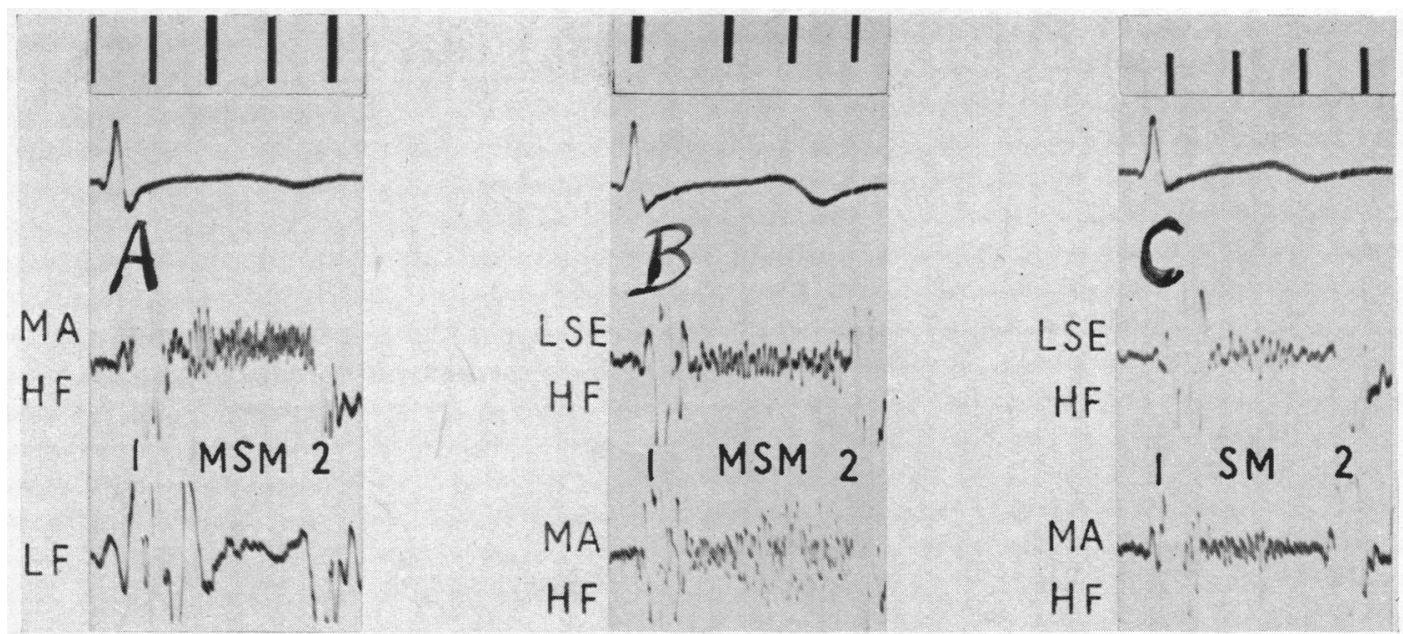

FIG. 6.-Serial recordings from one patient showing (A) pansystolic mitral murmur, (B) late systolic accentuation of this murmur and $(\mathrm{C})$ disappearance of the mitral and persistence of a midsystolic basal murmur.

only a mid-systolic murmur at the mitral area, presumably of basal origin. Phonocardiograms of mitral late systolic murmurs invariably demonstrated the pansystolic duration of the murmurs although clinically they may have been sufficiently faint in early systole to be inaudible in this phase. Occasionally late systolic murmurs may occur in the absence of organic heart disease; in the few examples studied the phonocardiogram showed no vibrations in early systole.

Complete recovery from mitral valvulitis may occur. Fig. 7A was recorded from a nine-yearold girl three weeks after the onset of her first attack of rheumatic fever: mitral systolic and diastolic murmurs were heard, and there was left atrial enlargement due to the mitral incompetence, but no generalized cardiac enlargement. Two weeks later complete clinical and radiological recovery had occurred, and the phonocardiogram (Fig. 7B) no longer showed mitral systolic and diastolic
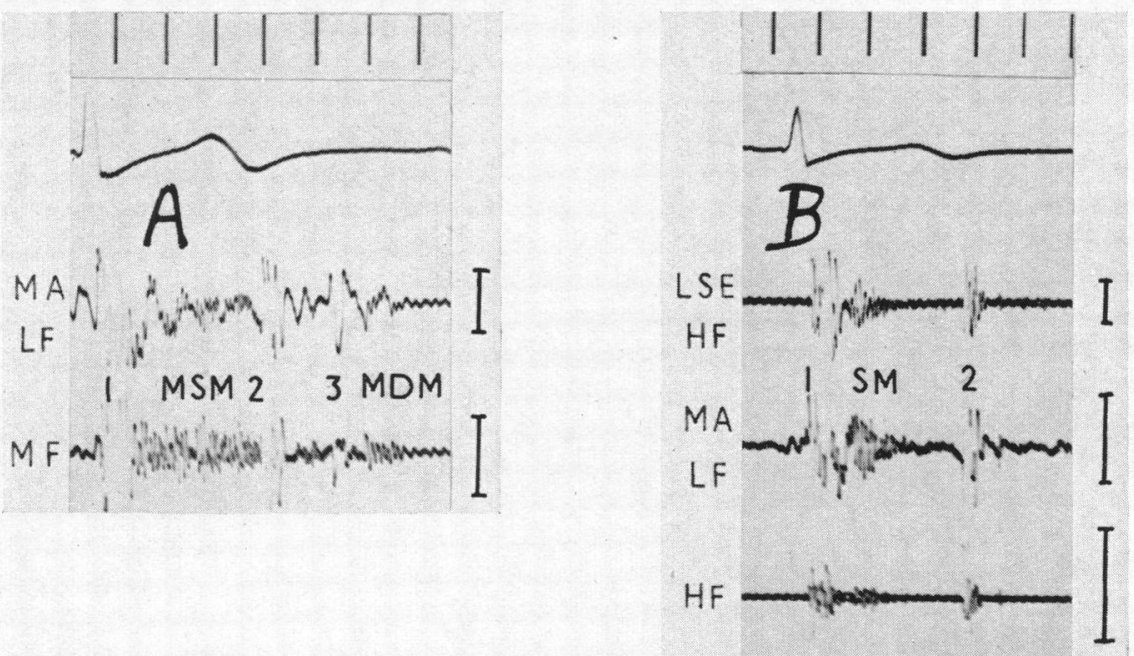

FIG. 7.-(A) Acute mitral valvulitis of three weeks duration, with mitral pansystolic and diastolic murmurs. (B) Recovery, no significant mitral murmurs detected. 
murmurs, but only a benign basal systolic murmur conducted to the mitral area. The degree of amplification used in these two phonocardiograms is indicated at the side of each tracing.

In patients with mitral valvulitis, systolic murmurs alone were rarely observed; diastolic murmurs were detected in addition to the systolic murmurs in 93 per cent of these patients.

\section{Mitral Diastolic Murmurs}

The earliest description of the apical diastolic murmur in acute carditis occurs in a case history cited by Bouillaud (1835). In a patient first seen on November 24, 1833, a systolic murmur and an extra sound were audible at the apex; by early December the signs had altered, and were described as "ticss ...tac ...tac ... sss". Thus an apical diastolic murmur was noted to develop, following a (?) third heart sound. In 1892 Sturges recognized that this murmur could occur in the absence of mitral stenosis, and that it might appear to be presystolic in timing in the presence of tachycardia. Coombs described the murmur in 1907 and in subsequent papers he noted that it was transient in some cases. In 1924 Coombs stated that the murmur was probably caused by acute valvulitis in cases of early rheumatic carditis. The cause of the murmur is still disputed: Bland and Jones (1952) considered that it might be due to relative mitral stenosis, but left ventricular enlargement is not present in early carditis at a time when this murmur is often first detected. Fishberg (1940) and Wood (1950) supported the valvulitis theory and noted the absence of diastolic murmurs in patients with cardiac enlargement of other ætiologies. Inflammation diminishes the flexibility of the valve cusps and gives rise to vegetations. These stiffened cusps and the surface irregularities set up eddy currents during the phase of rapid ventricular filling and cause the mitral diastolic murmur. With a slow heart rate the rapid-filling phase follows the third heart sound (Fig. 7A); during tachycardia it many occur during atrial systole (Fig. 8A).

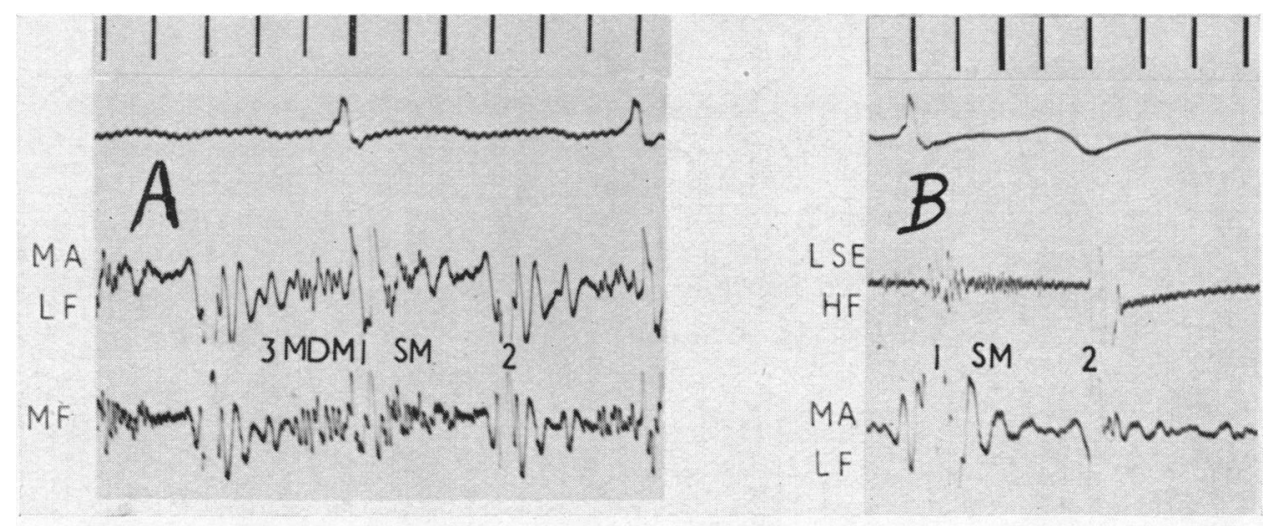

FIG. 8.-(A) Mitral diastolic murmur of acute caditis occurring during atrial systole in the presence of tachycardia. (B) Subsequent disappearance of mitral murmur.

The murmur may be clinically confused with a loud third heart sound owing to their similar pitch. The third sound usually occupies a frequency of 20-60 cycles/sec. and the murmur one of 40-100 cycles/sec. Thus in some cases a low-pass filter will demonstrate the third sound and murmur equally well (Fig. 2); but if the murmur occupies the higher range of frequencies a medium-pass filter shows the murmur better than the third sound (Fig. 7A). The duration of the third sound is $0.03-0.06 \mathrm{sec}$, whereas the diastolic murmur is of greater duration than $0.08 \mathrm{sec}$. Thus the phonocardiogram is of value in distinguishing between sound and murmur when the difference is clinically uncertain.

These mitral diastolic murmurs often disappeared, but no initial phonocardiographic distinction could be made between the transient and permanent murmurs. The characteristic fluctuating 
intensity of these murmurs made repeated observations necessary before it could be ascertained that a murmur had truly disappeared. The increased cardiac output associated with physical acitivity might elicit murmurs that had apparently disappeared during rest in bed. Therefore it was necessary to examine these children after mobilization before deciding that recovery was complete. The disappearance of the typical short mitral diastolic murmur of grade 1 intensity is shown in Fig. 8. In this patient the murmur was never heard subsequently, and complete recovery from carditis occurred.

However, murmurs of greater duration and intensity also proved transient. Fig. 9A was recorded from a patient suffering from mild aortic incompetence and a second attack of rheumatic fever; a long mitral diastolic murmur appeared five days later (Fig. 9B) and persisted for several weeks: no

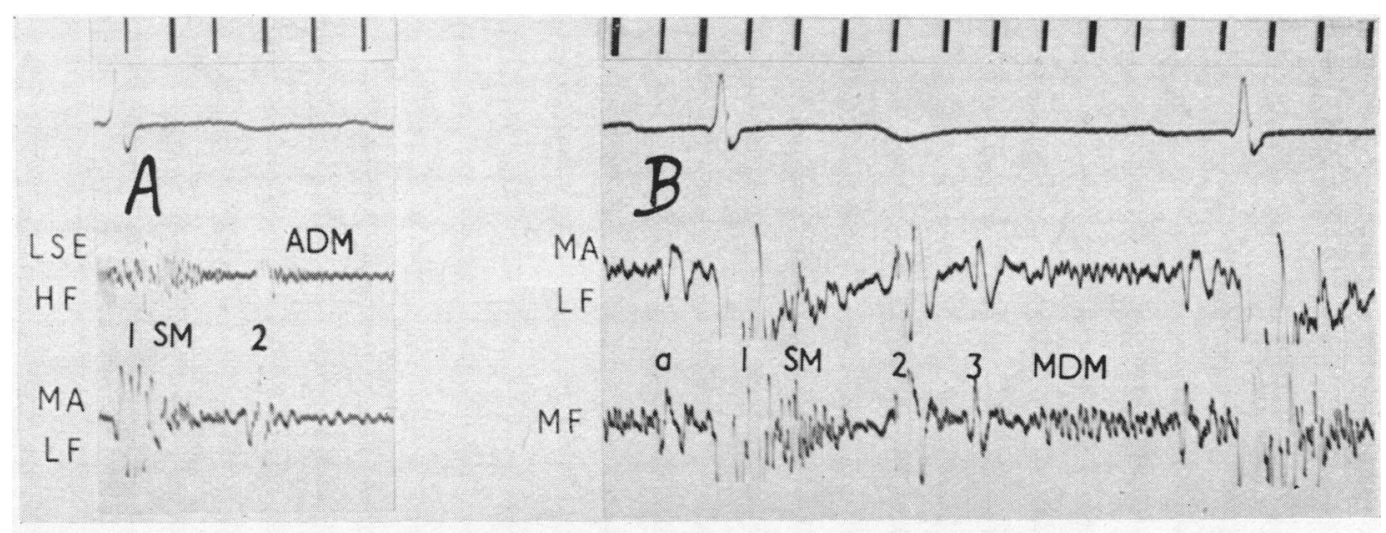

Fig. 9.-(A) Second attack of rheumatic carditis showing aortic diastolic murmur alone. (B) Development of long mitral diastolic murmur five days later.

mitral systolic murmur was detected at any time. The diastolic murmur then disappeared, and at the time of discharge from hospital the cardiac signs were identical with those found on admission.

The mitral diastolic murmur frequently occurred in the absence of a systolic murmur and was often the earliest sign of carditis to be detected. Furthermore, in patients without florid clinical signs, the detection of this murmur helped to confirm the diagnosis of rheumatic fever.

\section{Aortic Diastolic Murmurs}

Stokes (1854) and Walshe (1854) recognized the aortic diastolic murmur as a sign of acute rheumatic carditis. Coombs (1907) pointed out that the murmur occurred without peripheral signs of free aortic regurgitation, that it often first appeared during recovery, and that it was transient in some cases. The murmur is caused by a mild degree of aortic incompetence due to aortic valvulitis. On the phonocardiogram the murmur of established aortic incompetence is initiated by the second sound and is of decrescendo configuration and of long duration (Fig. 10); whereas the softer murmur of early rheumatic valvulitis is of the crescendo-decrescendo form (Fig. 11) described by Wells et al. (1949) and Leatham (1950), and is shorter in length. The aortic murmurs of grade 3 and 4 intensity occupy frequencies of $400-800$ cycles/sec., whereas the grade 1 and 2 aortic murmurs are frequently of higher pitch and therefore more difficult to record on the phonocardiogram.

Recovery from aortic valvulitis may occur, with disappearance of the diastolic murmur. Fig. 12A was recorded from a patient with an aortic murmur of grade 1 intensity. The murmur was no longer heard during convalescence, even after increased physical activity, and no murmur was demonstrated at this time (Fig. 12B), even using a greater degree of amplification than for recording Fig. 12A. 


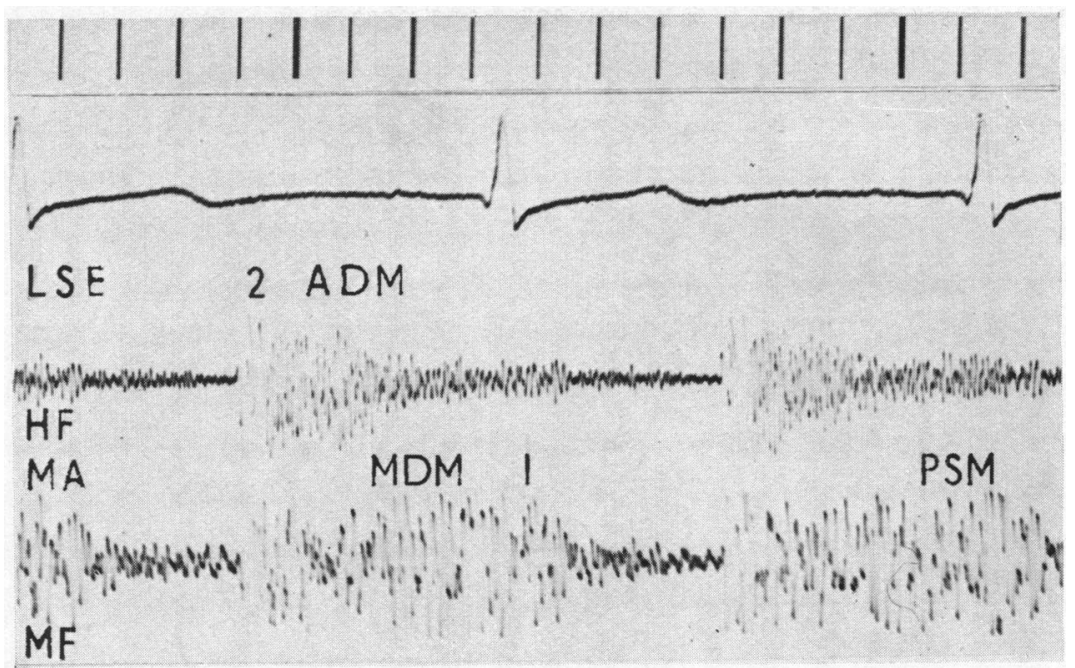

Fig. 10.-Decrescendo murmur of established aortic incompetence.

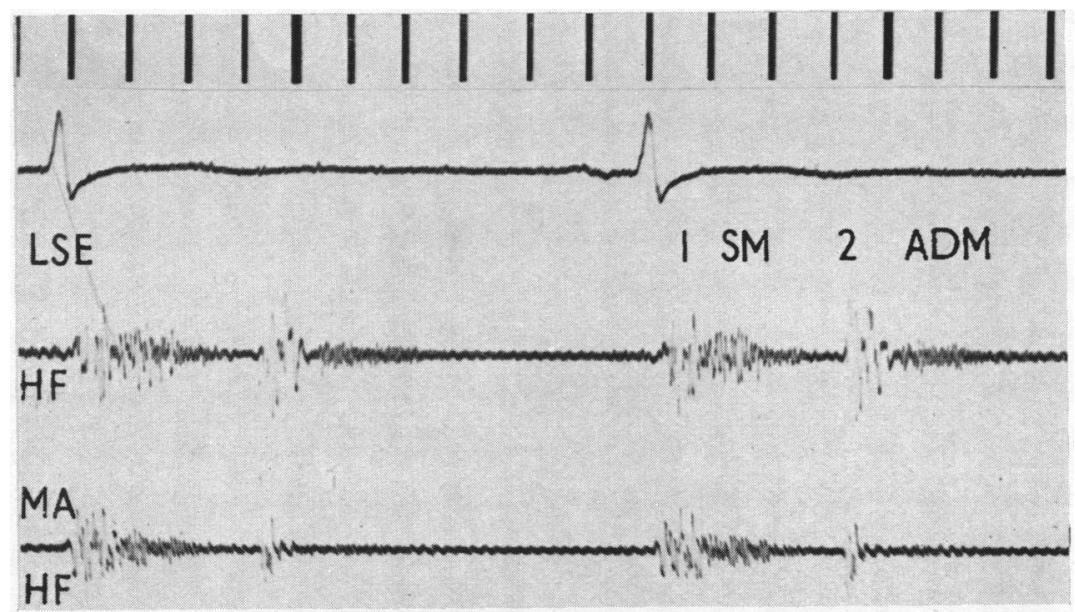

FIG. 11.- "Crescendo-decrescendo" murmur of early acute aortic incompetence.

Pinpoint perforation of an aortic valve cusp may occasionally occur in acute rheumatic carditis and be the cause of the sudden appearance of a grade 4 intensity aortic diastolic murmur (Fig. 13A). Thrombotic occlusion of the perforation presumably accounted for the diminishing intensity of the murmur shown in subsequent records from this patient (Fig. 13, B and C). This change of intensity was confirmed by the increased amplification necessary to record the murmur.

Aortic stenosis is never seen in early rheumatic carditis, and the distinction between basal systolic murmurs of aortic and pulmonary origin has not yet been made by phonocardiography.

\section{Phenylephrine}

Phonocardiography alone may ascertain the presence of faint diastolic murmurs, especially those of mitral origin that may be confused with a third sound clinically. Further clinical con- 


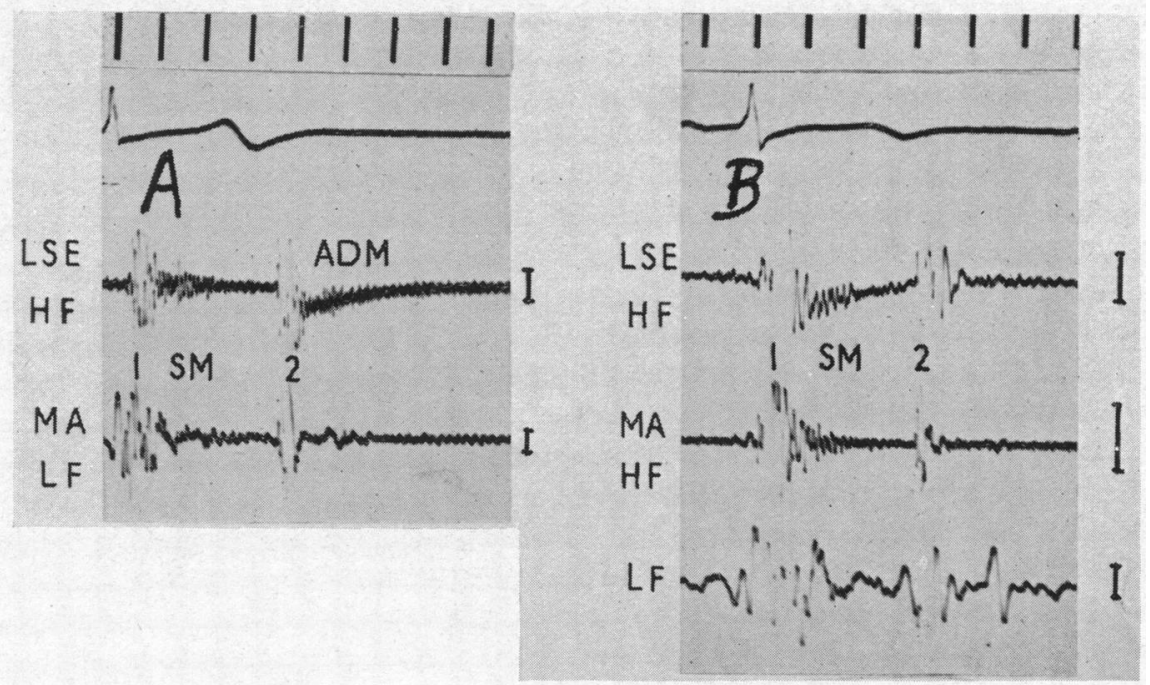

FIG. 12.-(A) Aortic diastolic murmur of grade one intensity in acute carditis. (B) Disappearance of aortic murmur.

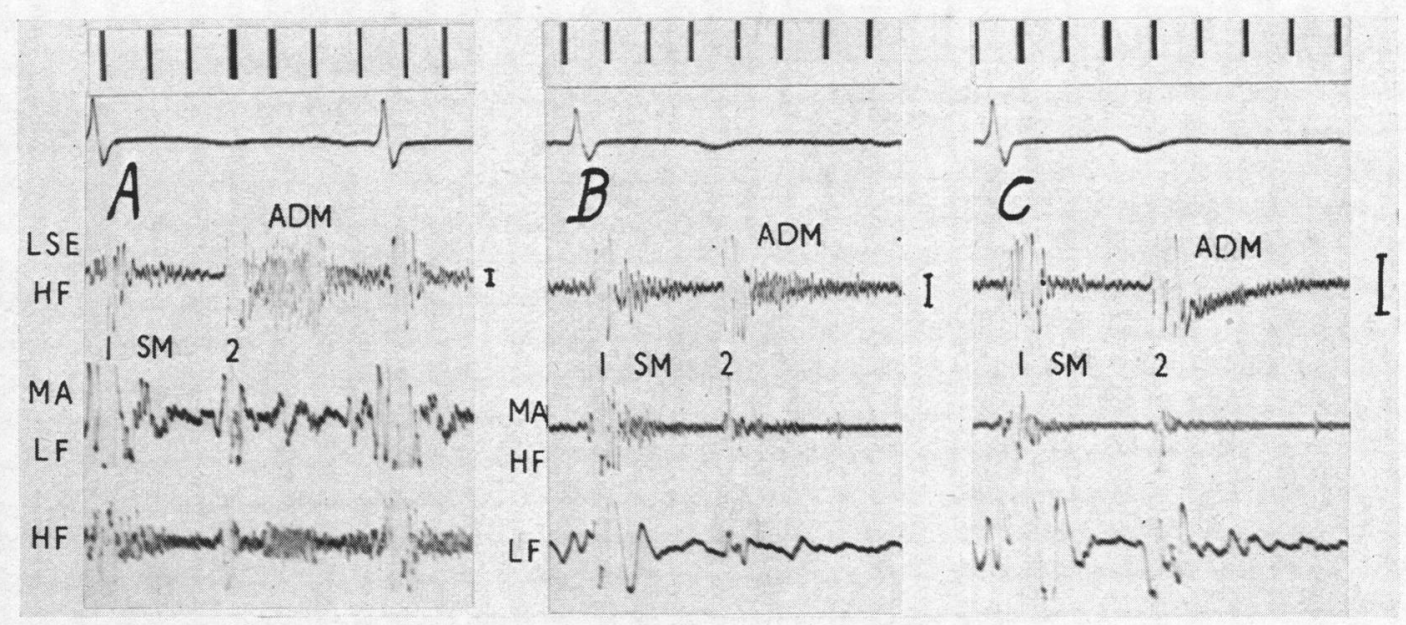

FIG. 13-(A) Aortic diastolic murmur of grade 4 intensity due to perforated aortic valve cusp in acute rhuematic carditis. (B) and (C). Subsequent diminution of intensity murmur, attributed to thrombotic occlusion of the perforation.

firmation can be obtained by the use of intravenous phenylephrine (Besterman, 1951). Phonocardiograms recorded before and after the injection provide a permanent record of the transient accentuation of murmurs produced by the drug. Fig. 14A was obtained from a patient in whom the presence of both diastolic murmurs was doubtful clinically. No definite murmurs were demonstrated either on this phonocardiogram or on another recorded eight days later, but phenylephrine was then injected and mitral and aortic diastolic murmurs of grade-one intensity were clearly shown (Fig. 14B). 
Tachycardia alone may mask mitral diastolic murmurs clinically and on the phonocardiogram. Cardiac slowing by carotid sinus pressure may be necessary before the presence of the murmur is verified. Phenylephrine has also been used for this purpose. Fig. 15A was recorded from a nervous child with tachycardia and aortic valvulitis, but a further record (Fig. 15B) showed the aortic diastolic murmur at the left sternal edge and at the mitral area. No distinct mitral diastolic murmur was heard at the apex until the heart rate was slowed by intravenous phenylephrine (Fig. 15C).

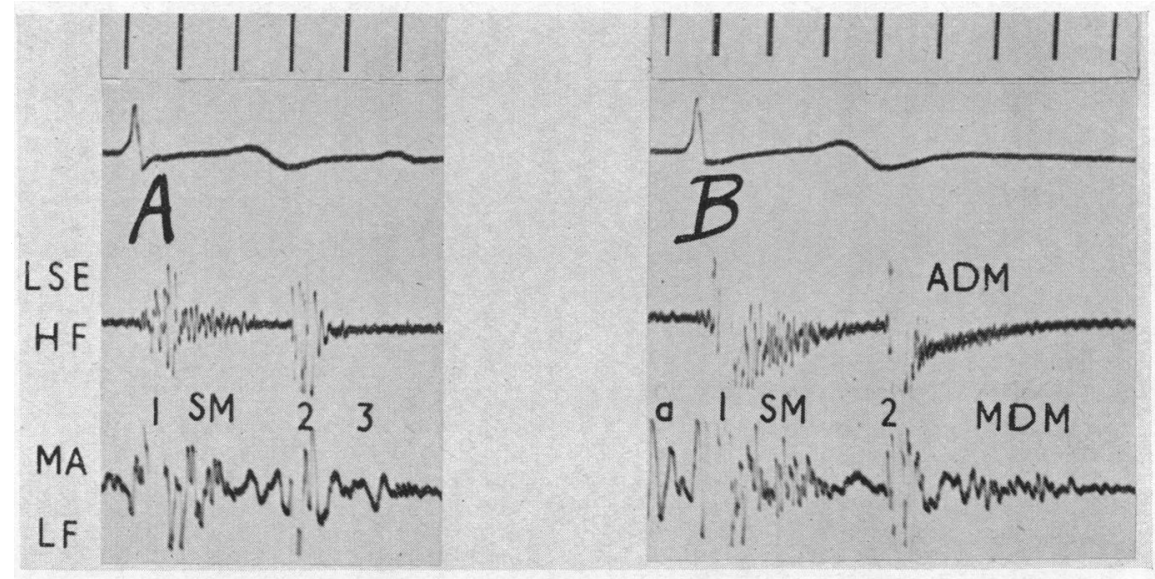

FIG. 14.-(A) Recording from patient with acute rheumatic fever in whom the presence of significant murmurs could not be ascertained. (B) Demonstration of mitral and aortic diastolic murmurs following an injection of phenylephrine intravenously.
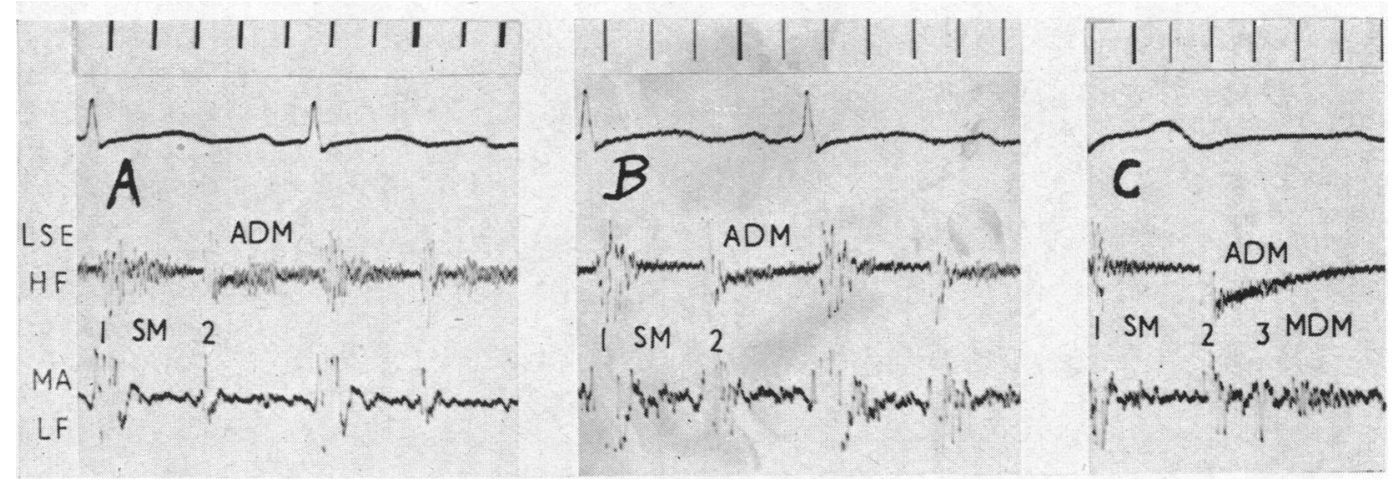

FIG. 15.-(A) Acute aortic valvulitis and tachycardia. (B) With aortic murmur conducted to mitral area. (C) Bradycardia following phenylephrine demonstrates distinct mitral diastolic murmur.

\section{Pericarditis}

Phonocardiography is rarely necessary to distinguish between rubs and mitral murmurs. Owing to the high pitch of both rubs and aortic diastolic murmurs, these two may occasionally be confused clinically. The distinction may also be difficult to make by phonocardiography, but a diastolic rub may be distinguished from a murmur by the later onset of the rub and the presence of the rub in other phases of the cardiac cycle-atrial and ventricular systole. Fig. 16 illustrates a rub in systole and diastole without murmurs. 


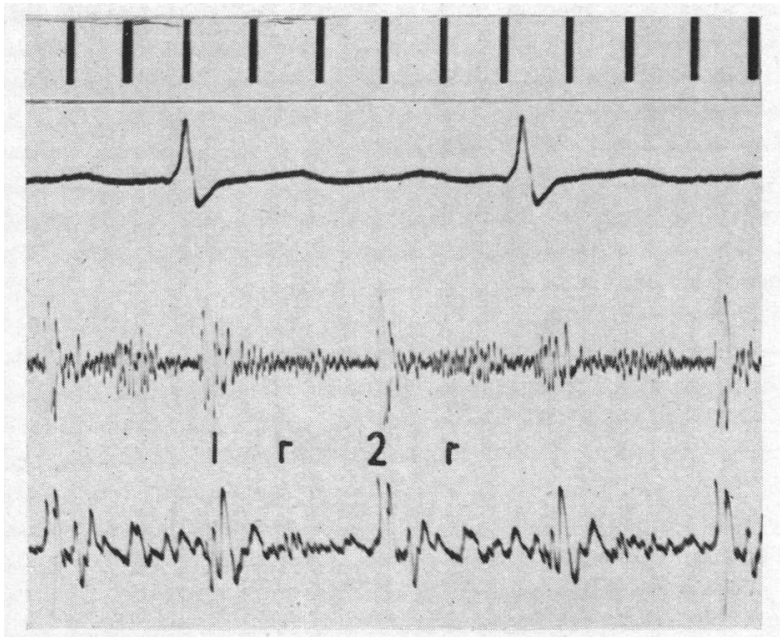

FIG. 16.-Acute rheumatic pericarditis with systolic and diastolic rubs.

\section{SUMMARY}

As the diagnosis of rheumatic carditis depends largely on auscultation, phonocardiography has been applied to the study of the murmurs produced by acute valvulitis. When clinical interpretation is uncertain, phonocardiography may aid the initial diagnosis. The duration of a systolic murmur in the mitral area is shown conclusively on the phonocardiogram; the distinction between a short mitral diastolic murmur and a third heart sound may also be made, and the presence of a soft aortic diastolic murmur can be confirmed by phonocardiography.

Phonocardiography provides objective confirmation of auscultatory findings. Such corroboration is of particular value in the study of the changing murmurs of acute rheumatic carditis, and in recording transient accentuation of murmurs induced by phenylephrine. Furthermore, calibration of the amplification employed in serial phonocardiograms provides some evidence of changing intensity of murmurs.

In the present study phonocardiography also drew attention to a clinical sign; accentuation of the third heart sound in mitral incompetence.

In the presence of tachycardia, apical diastolic murmurs cannot always be distinguished on the phonocardiogram. With a normal heart rate the mitral diastolic murmur of Carey Coombs can be readily differentiated from a third heart sound and is a frequent finding in early carditis.

I am indebted to Dr. Paul Wood, Dr. E. G. L. Bywaters, and Dr. Thomas for their helpful criticism and advice; to Mr. J. K. Harrison for technical assistance and to the G.P.O. Research Station, Dolis Hill, for the loan of the audiofrequency spectrometer.

This paper is part of an M.D. thesis submitted in August, 1954.

\section{REFERENCES}

Barlow, G. (1846). Trans. Path. Soc. London, 1, 220.

Besterman, E. M. M. (1951). Brit. med. J., 2, 205.

-, and Harrison, J. K. (1953). Brit. Heart J., 15, 130.

- , and Thomas, G. (1953). Brit. Heart J., 15, 113.

Bland, E. F., and Jones, T. D. (1952). Ann. intern. Med., 37, 1006.

Bouillaud, J. (1835). Traité Clinique des Maladies du Ceur. 1st ed. Paris.

Brigden, W., and Leatham, A. (1953). Brit. Heart J., 15, 55.

Castro, A. V., Watkins, C., Rubio, C., and Battilana, G. D. (1947). Rev. argent. Cardiol., $15,25$.

Cheadle, W. B. (1889). Lancet, 1, 821, 871, and 921 . 
Coombs, C. F. (1907). Bristol med-chir. J., 25, 193. (1924). Rheumatic Heart Disease. 1st ed. Bristol.

Cossio, P. (1937). Rev. argent. Cardiol., 4, 301 and 383.

Elliotson, J. (1830). On Recent Improvements in the Art of Distinguishing the Various Diseases of the Heart. Lumleian Lectures, 1829, London.

Fishberg, A. M. (1940). Heart Failure. 2nd ed. London.

Hope, J. (1839). A Treatise on the Diseases of the Heart and Great Vessels. 3rd ed. London.

Johnston, F. D. (1935). Amer. Heart J., 10, 654.

Leatham, A. (1950). Proc. R. Soc. Med., 43, 309.

(1951). Brit. Heart J., 13, 153.

(1952). Brit. med. Bull., 8, 333.

Levine, S. A. (1945). Clinical Heart Disease. 3rd ed. Philadelphia.

Lewis, Sir Thoms (1915). Lectures on the Heart. 1st ed. New York.

Lian, C., and Racine, M. (1933). Ann. Med., 34, 75.

McKee, M. H. (1938). Amer. Heart J., 16, 79 and 88.

Owen, S. H. (1886). Med. Chron. Manchester, 4, 295.

Schwarzchild, M. M., and Feltenstein, M. D. (1934). Amer. Heart J., 10, 453.

Sprague, H. B., and White P. (1926). Amer. Heart J., 1, 629.

Stokes, W. (1854). Diseases of the Heart and Aorta. 1st ed. Dublin.

Sturges, O. (1892). Lancet, 1, 621. (1894). Brit. med. J., 1, 505, 561, and 623.

Taquini, A. C., Massell, B. F., and Walsh, B. J. (1940). Amer. Heart J., 20, 295.

Thayer, W. S. (1925). Bull. Johns Hopk. Hosp., 36, 99.

Todd, R. B. (1849). Lond. med. Gaz., 43, 660.

Walshe, W. H. (1854). Diseases of the Lungs, Heart and Aorta. 2nd ed. London.

Wells, B., Rappaport, M. B., and Sprague, H. B. (1949). Amer. Heart J., 37586.

Wood, P. (1950). Diseases of the Heart and Circulation. 1st ed. London.

- (1954). Brit. med. J., 1, 1051 and 1113. 